\title{
Voter Reactions to Candidate Background Characteristics Depend on Candidate Policy Positions
}

\author{
Pedersen, Rasmus T.; Dahlgaard, Jens Olav; Citi, Manuele
}

\author{
Document Version \\ Accepted author manuscript \\ Published in: \\ Electoral Studies \\ DOI: \\ 10.1016/j.electstud.2019.102066 \\ Publication date: \\ 2019 \\ License \\ CC BY-NC-ND
}

Citation for published version (APA):

Pedersen, R. T., Dahlgaard, J. O., \& Citi, M. (2019). Voter Reactions to Candidate Background Characteristics Depend on Candidate Policy Positions. Electoral Studies, 61, [102066].

https://doi.org/10.1016/j.electstud.2019.102066

Link to publication in CBS Research Portal

\section{General rights}

Copyright and moral rights for the publications made accessible in the public portal are retained by the authors and/or other copyright owners and it is a condition of accessing publications that users recognise and abide by the legal requirements associated with these rights.

\section{Take down policy}

If you believe that this document breaches copyright please contact us (research.lib@cbs.dk) providing details, and we will remove access to the work immediately and investigate your claim.

Download date: 26. Apr. 2023

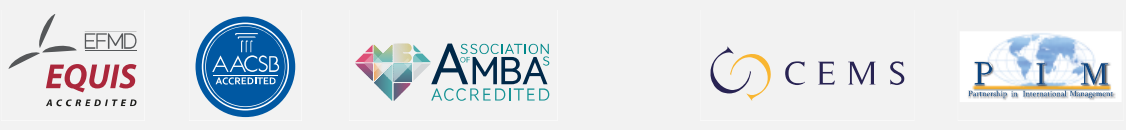




\section{Voter Reactions to Candidate Background Characteristics Depend on Candidate Policy Positions}

\section{Rasmus T. Pedersen, Jens Olav Dahlgaard, and Manuele Citi}

Journal article (Accepted manuscript*)

\section{Please cite this article as:}

Pedersen, R. T., Dahlgaard, J. O., \& Citi, M. (2019). Voter Reactions to Candidate Background Characteristics Depend on Candidate Policy Positions. Electoral Studies, 61, [102066]. https://doi.org/10.1016/j.electstud.2019.102066

\section{DOI: 10.1016/j.electstud.2019.102066}

* This version of the article has been accepted for publication and undergone full peer review but has not been through the copyediting, typesetting, pagination and proofreading process, which may lead to differences between this version and the publisher's final version AKA Version of Record.

Uploaded to CBS Research Portal: May २०२०

(C) 2019. This manuscript version is made available under the CC-BY-NC-ND 4.0 license http://creativecommons.org/licenses/by-nc-nd/4.0/ 


\title{
Voter REACTIONS TO CANDIDATE BACKGROUND CHARACTERISTICS
}

\section{Depend on Candidate Policy Positions}

\author{
Rasmus Tue Pedersen \\ The Danish Center for Social Science Research (VIVE) \\ Jens Olav Dahlgaard \\ Copenhagen Business School \\ Manuele Citi \\ Copenhagen Business School
}

\begin{abstract}
Do personal background characteristics of a political candidate affect voter evaluations when voters also know the candidate's policy position? Several studies have shown that voters infer personal traits and policy positions from candidate characteristics such as gender, family background and occupation. However, in most elections, voters do not evaluate candidates absent of any policy information. We investigate whether the influence of personal background characteristics vanishes when policy information regarding a candidate is available to the voters. Using a survey experiment, we confirm that voters infer both personal traits and policy positions from the background characteristics of a candidate, and we furthermore show that explicit information on policy positions moderates the relationship between background characteristics and candidate evaluations. However, policy information does not simply crowd out the effects of candidate background characteristics. Instead, policy information can change the valence of background characteristics, turning otherwise disadvantageous characteristics into an electoral advantage.
\end{abstract}

This work was supported by the Danish Council for Independent Research, Social Sciences (grant number: DFF-6109-00052). 


\section{Introduction}

When voters choose between political candidates, they are not just choosing between candidates with different party labels and policy positions, they are also choosing between candidates with different personal background characteristics. These personal characteristics ostensibly matter to voters. Recent studies show, for example, that voters tend to prefer female candidates to male candidates (Kirkland and Coppock 2017; Wüest and Pontusson 2017; Aguilar, Cunow and Desposato 2015). Conversely, voters are less fond of candidates with high personal incomes and certain occupations (Carnes and Lupu 2016; Campbell and Cowley 2014a; 2015).

The link between personal characteristics and electoral popularity of a candidate can be explained by two voter heuristics. First, voters infer personality traits from a candidate's background. The gender, occupation and income of a political candidate affect, for example, the degree to which the candidate is perceived by voters to be understanding, approachable, and competent (Carnes and Lupu 2016; Campbell and Cowley 2014; Kirkland and Coppock 2017). Such inferences from background characteristics to traits are likely to influence the electoral popularity of candidates, as perceived traits have clear effects on electoral support (Mccurley and Mondak 1995; Funk 1999; Mondak and Huckfeldt 2006; Adams et al. 2011; Franchino and Zucchini 2015). Second, voters may also infer policy positions from a candidate's background. Voters tend to assume, for example, that female candidates and candidates with a working-class background favor left-leaning policies (McDermott 1998; Carnes and Lupu 2016; Carnes and Sadin 2015; Arnesen, Duell and Johannesson 2019).

In most elections, however, inferences from a candidate's background characteristics to the candidate's policy positions may be superfluous to voters, because political candidates readily supply information on policy positions, both through their party label and by taking explicit positions on policy issues. It is a common notion in the literature on candidate characteristics that such information can overwhelm and attenuate the effects of personal background characteristics when voters evaluate candidates (e.g., McDermott 1998; Campbell and Cowley 
2015; Ono and Burden 2018). However, in reality, few studies have specifically investigated the degree to which the link between candidate characteristics and voter evaluations depends on the absence or presence of explicit policy information (Carnes and Sadin 2015; Kirkland and Coppock 2017; Arnesen, Duell and Johannesson 2019).

In this paper, we add to the study on candidate characteristics and vote choice by investigating how candidate background characteristics and policy information interact when voters evaluate political candidates. We do so using a survey experiment with 2,400 Danish voters. First, we explore the degree to which voters use a candidate's gender, family background, and occupation to infer candidate traits and policies. Here, we contribute to the literature by utilizing comprehensive measures of trait perceptions, specifically perceptions of competence and warmth (Judd, James-Hawkins, Yzerbyt, and Kashima 2005). We find no effects of candidate gender, but family background and occupation clearly affect voter perceptions of candidate competence, warmth, and position on the political left-right scale.

Second, our study revisits the widespread, yet rarely tested, assumption that policy information crowds out the effects of candidate background characteristics. Here, we contribute by investigating the effects of specific policy positions rather than party cues (Kamin 1958; Kam 2007; Sen 2017; Kirkland and Coppock 2017). We find that the assumption of crowding out is, in a sense, both right and wrong. Our results do confirm that when voters are given information about the policies of a candidate, such information do in some cases crowd out the effects of background characteristics. However, because voters make multiple inferences from background characteristics, and because policy information affects these inferences unevenly, policy information does not just remove the effects of candidate characteristics on vote choice. Rather, providing voters with policy information can lead to preference reversals, turning otherwise undesirable background characteristics into desirable characteristics in the eyes of the voters. 


\section{Candidate Characteristics and Vote Choice}

Personal characteristics of political candidates seem to matter to the voters (Campbell and Cowley 2014a; Carnes and Lupu 2016; Kirkland and Coppock 2017). To explain how such characteristics of candidates may affect voters, the theoretical framework that we present and apply in this article focuses on two types of heuristics that the voters may use when presented with the personal background characteristics of candidates. First, voters might use candidate characteristics to infer something about a candidate's personal traits (e.g., Campbell and Cowley 2014b). Second, voters might use candidate characteristics to infer something about a candidate's policy position (e.g., Kirkland and Coppock 2017). While we focus on these two types of inferences in this study, it should be noted that candidate background characteristics might also affect vote choices in other ways. Voters may for example ascribe - consciously or unconsciously - to ideals of descriptive representation (Pitkin 1967). Thus, they may prefer a candidate with of a certain gender or race because they find inherent value in being represented by politicians with these characteristics (West 2017). Before delving into the exact relationship between specific background characteristics and voter evaluations, we first elaborate on the potential importance of these two types of heuristics for electoral outcomes.

The electoral relevance of the first heuristic, inferring from candidate background characteristics to candidate traits, obviously depends on the extent to which such personality traits matter to voters when they choose for whom to vote. That there is a relationship between trait perceptions and voter preferences for candidates was established decades ago (Kinder, Peters, Abelson, and Fiske 1980; Funk 1999). While previous studies suggested that trait perceptions were largely endogeneous to party and issue positions (Bartels 2002; Peterson 2005), several later studies have shown that trait perceptions have an independent causal effect on the choices made by voters (Fridkin and Kenney 2011; Ohr and Oscarsson 2013; Laustsen 2017). Studies on candidate characteristics and vote choice have, however, often relied on single-item measures of, for example, competence (Peterson 2018). In this paper, we use a model of trait 
perceptions, the stereotype content model (SCM), which posits that people assess other individuals or groups on two fundamental dimensions, competence and warmth (Judd, JamesHawkins, Yzerbyt, and Kashima 2005). The dimension of warmth reflects traits related to an individual's or group's intentions, such as friendliness and helpfulness, whereas the dimension of competence captures traits related to the individual's or group's abilities, such as intelligence and skills in general (Fiske et al. 2007; Koch and Obermaier 2016). While the SCM-model does not necessarily encapsulate all the traits that voters assess political candidates on, several studies confirm that voters do assess politicians and political candidates along these two dimensions, and perceptions regarding both dimensions have substantial effects on voters' support for a politician. (Laustsen 2017; Pedersen 2017). Crucially, voters do not just want politicians that are competent, they also care about the warmth of politicians, because a high level of warmth indicates that the politicians will use their competences benevolently (Laustsen and Bor 2017). Furthermore, while the two dimensions in the SCM-model are correlated, the existing studies demonstrate that both dimensions are relevant to investigate at the same time, as experimental treatments with a positive effect on one dimension can have no effect or even a negative effect on the other dimension (e.g., Pedersen 2017; Laustsen and Bor 2017).

The electoral relevance of the second type of inference, from candidate characteristics to candidate policy position, is fairly obvious. According to the classical Downsian model of electoral competition, voters prefer the candidate that is closest to the voter's own policy positions (Downs 1957). This prediction has been confirmed in a host of empirical studies (e.g. Ansolabehere, Rodden, and Snyder 2008), including studies within the Danish context where our study takes place (Bengtsson, Hansen, Harðarson, Narud, and Oscarsson 2014; Hansen and Pedersen 2014). In the following sections, we address how three specific candidate characteristics— gender, family background, and occupation—-may affect voter inferences regarding the traits and policy positions of a candidate, and how these background 
characteristics may ultimately affect vote choice. ${ }^{1}$

\subsection{Gender and Voter Inferences}

The underrepresentation of women among politicians has often been explained as a result of voters being biased against women (Lawless 2009; Anzia and Berry 2011). In line with this explanation, earlier studies found that women were generally perceived to be less competent than men, at least on some policy issues, which might make voters less likely to vote for them (Huddy and Terkildsen 1993). However, these finding have been strongly countered by more recent studies, which generally find no bias against female politicians (Campbell and Cowley 2014b; McElroy and Marsh 2010). Furthermore, recent studies focusing specifically on perceived competence have also found women to be perceived as being just as competent as male politicians (Carnes and Lupu 2016). Thus, taken together, the existing results on this issue arguably does not support the notion that voters are biased again women on perceptions of competence. Therefore, we do not expect gender differences on voter perceptions of candidate competence.

On the question of warmth, however, there is reason to expect that voters perceive male and female candidates differently. Women are generally perceived to be higher on the warmth dimension than men (Huddy and Terkildsen 1993). Correspondingly, Campbell and Cowley (2014b) find that female candidates are perceived to be more "approachable," a term that probably reflects perceptions of warmth although not traditionally used to measure this trait. This leads to the expectation that voters perceive female candidates to have higher warmth than male candidates (hypothesis 1A).

\footnotetext{
${ }^{1}$ While we focus on gender, parents and occupation, voters may also infer the ideology of a candidate from, e.g., the candidate's religion and race (Brady and Sniderman, 1985; Campbell, Green, and Layman, 2011; Lerman and Sadin, 2016).
} 
Gender can also play a role when voters make inferences regarding the policy positions of a candidate. Voters perceive female candidates as being more to the left on the political spectrum than their male counterparts (Huddy and Terkildsen 1993; McDermott 1998, Koch 2000, although see Carnes and Lupu 2016). Thus, we expect that voters perceive female candidates to be more to the left than male candidates (hypothesis 1B).

How should these inferences on candidate gender then be expected to affect vote choice? Given that women have no apparent disadvantage on perceived competence, and that they do have an advantage on perceived warmth, female candidates may have an electoral advantage over male candidates, since the perceived warmth has a strong effect on voters' overall evaluation and support for politicians (Laustsen and Bor 2017). That women are perceived to be more left-leaning than men, should have no clear net effect on electoral popularity, seeing as that will make them more popular with some votes and less popular with others. Several recent experimental studies do indeed find that voters tend to prefer female candidates (Aguilar, Cunow, and Desposato 2015; Kirkland and Coppock 2017; Wüest and Pontusson 2017; Teele, Kalla, and Rosenbluth 2018). This leads to the hypothesis that voters are more likely to vote for a female candidate than a male candidate (hypothesis 1C).

\subsection{Family Background and Voter Inferences}

Compared to the many studies on voters' inferences from candidate gender, the literature on voter inferences from family background is relatively sparse. One of the few studies to investigate the effects of candidate family background found that family background had no significant effects on voters' perception of candidate competence (Sadin 2015). In line with this, we do not see a strong theoretical argument for family background to affect voters' perceptions of candidate competence. However, on voter perceptions of candidate warmth, it is more reasonable to expect the candidate's family background to have an effect similar to the effect of the candidate's own occupation. As we discuss in the next subsection, individuals from the

working class are generally perceived to possess traits related to warmth (Carnes and Lupu 2016). 
Someone raised in a working-class environment is likely to be perceived as relatively similar to the current working class on this trait, and we therefore expect that voters perceive candidates with working-class parents to have higher warmth than candidates with upper-middle class parents (hypothesis 2A).

For similar reasons, voters may also infer policy positions from the family background of a candidate. This expectation is in line with Carnes and Sadin (2015), finding that a candidate with a working-class family background was generally perceived to be more economically progressive than a candidate from an upper-middle class background. Thus, we also expect that voters perceive candidates with working-class parents to be more to the left than candidates with upper-middle class parents (hypothesis 2B). In sum, based on the extant literature, one should expect voters to infer similar traits and policy positions for female candidates and candidates from a working-class family background, namely that they are warmer and more left-leaning on the political spectrum. While the popularity of left-leaning candidates are of course dependent on the left-right position of the voters, voters across the political spectrum should generally prefer warmer candidates, leading to the hypothesis that voters are more likely to vote for candidates with working-class parents than candidates with upper-middle class parents (hypothesis 2C).

\subsection{Candidate Occupation and Voter Inferences}

There are several reasons as to why voters may be particular apt to infer traits and policy positions from the occupation of a candidate. First, while candidates are usually assigned a gender and parents with certain occupations at birth, candidates are- to some degree-able to choose their own occupation. Thus, voters may take occupation as a relatively strong signal regarding the skills and dispositions of a candidate. Second, votes may also infer other background characteristics from a candidate's occupation, for example the level of education and income. This is relevant because even in cases where a candidate's occupation does not directly affect voter perceptions of candidate qualifications for office, education may do so. Here, candidates with a university degree are generally perceived to be more qualified than candidates without a degree (Carnes and Lupu 2016, see also Gift \& Lastra-Anadón 2018 who show that 
voters respond differently to graduates from elite and non-elite schools). Similarly, Campbell and Cowley (2014b) found that candidates with lower levels of education are perceived to be less “experienced." While these studies do not directly measure perceptions of competence, we therefore expect that voters perceive working-class candidates to have lower competence than upper-middle class candidates (hypothesis 3A).

While working-class candidates may have a disadvantage on perceptions of competence, they have an advantage on perceived warmth. Working-class candidates are perceived to be more likely to understand problems faced by people such as themselves (Carnes and Lupu 2016), and people without university education are perceived to have a higher level of approachability (Campbell and Cowley 2014b). Similarly, candidates with high personal incomes are also seen as less approachable (Campbell and Cowley 2014b). It is important to note that there can also be differences across different types of occupations within a certain class of jobs. For example, while lawyers and doctors are both upper-middle class occupations, lawyers are perceived to be markedly lower on "approachability" than doctors (Campbell and Cowley 2014b). This finding is important for our experiment, where we use the occupation of lawyer. We revisit this issue of heterogeneity within social classes in the discussion. In sum, the existing studies leads to the hypothesis that voters perceive working-class candidates to have higher warmth than upper (middle) class candidates (hypothesis 3B).

Voters may also be quick to infer policy positions from a candidate's own occupation. Just as voters infer that candidates with working-class parents are left-leaning (Carnes and Sadin 2015), voters also seem to think that candidates with a working-class occupation are left-leaning. Carnes and Lupu (2016) find such occupation-based inferences in Britain, while results from the United States and Argentina are statistically insignificant. We consider the results from Britain to be predictive of the results in a Danish context, and we therefore expect that voters perceive working-class candidates to be more to the left than upper (middle) class candidates (hypothesis 3C). 
What might all the voter inferences on occupation mean for the candidate once the voter is in the voting booth? On the one hand, working-class candidates might be less preferred due to lower levels of perceived competence; on the other hand, they might be more preferred due to the higher levels of perceived warmth. The existing results on vote choice point towards an overall advantage for working-class candidates. Candidates without university degrees seem to be more popular than candidates with university degrees, and candidates with high incomes are relatively unpopular among the voters (Campbell and Cowley 2014b; Wüest and Pontusson 2017). Comparing the electoral popularity of a business owner versus a factory worker, Carnes and Lupu (2016) find insignificant differences in vote choice, but the results do also point towards a slight advantage for the factory worker. Finally, we use a lawyer as the upper-middle class occupation in our experiment, and candidates with this occupation seem to be particularly unpopular among voters (Wüest and Pontusson 2017; Teele, Kalla, and Rosenbluth 2018). We therefore expect that voters are more likely to vote for working-class candidates than upper-middle class candidates (hypothesis 3D).

\section{The Role of Policy Information}

It is almost a truism that the policy position of a candidate can affect voters' evaluation and support of this candidate. This is clearly also the case in the Danish context. The self-placement of Danish voters on the left-right scale has traditionally been the single best predictor of their party choice (Bengtsson, Hansen, Harðarson, Narud, and Oscarsson 2014; Hansen and Pedersen 2014). Thus, when voters are provided with information regarding the policy positions of a candidate, such information should be expected to affect voter evaluations of the candidate.

Policy information might even be so important to the voter that it not only affects evaluations of candidates more than personal candidate characteristics do; the policy information may even crowd out the effects of personal background characteristics. In fact, it is a common assumption in the literature on candidate characteristics and voter evaluations that personal characteristics is a low-information heuristic, primarily used by voters when candidate policy 
information is absent (e.g., McDermott 1998; Campbell and Cowley 2015; Ono and Burden 2018; Crowder-Meyer et al. 2018; Gift \& Lastra Anadón 2018). There is some empirical support for this assumption. In an early experiment, Kamin (1958) found that information on candidates' party affiliation crowded out effects of candidate ethnicity. Likewise, later experiments have found that party labels on judicial nominees crowd out the influence of ethnicity and race in assessments of such nominees (Kam 2007; Sen 2017). Kirkland and Coppock (2017) generally find weak effects of background characteristics such as gender and age, but also find that information on party affiliation tend to crowd out the influence of candidate experience. This finding is further supported by a recent study, which shows that Norwegian voters care more about the issue position than the social characteristics of candidates (Arnesen, Duell, and Johannesson 2019). ${ }^{2}$

It is important to note that, with the exception of Arnesen, Duell, and Johannesson (2019), the existing studies all test the crowding-out effect of party cues, not just policy information. This focus on party cues is entirely reasonable, in particular given the key role played by party cues in American elections. However, while party labels convey information to the voter about the policy positions of the candidate (Kirkland and Coppock 2017), party cues also affect voters as markers of social identity and through an in-group versus out-group dynamic (Greene 1999).

Thus, based on the existing studies it is still not known whether policy information alone is sufficient to crowd out the effects of personal background characteristics. This limitation is important, because the role of party cues differ markedly across electoral contexts. First, party identification among voters differ substantially across countries, and few countries can match the

\footnotetext{
${ }^{2}$ Carnes and Sadin (2015) conduct two separate experiments, one of which contains party labels and one that does not. This study indicates that effects of background characteristics can be robust to the inclusion of party cues, but it does not provide an actual estimate of the crowding out effect (Nor does it claim to do).
} 
level of partisanship currently found in the US (Lupu 2015). For example, while surveys also show party identification in Denmark to be substantial, $42 \%$ of voters switched parties from the 2011 national election to the next national election in 2015 (Hansen and Stubager 2017, p. 34). Second, in proportional electoral systems voters can choose between multiple candidates from each political party. This is also the case in the Danish context. Depending on their exact municipality, a voter in the 2017 municipal election could choose between 25-251 candidates, most of whom represented one of the 6-13 viable parties in the municipality. ${ }^{3}$ To be clear, party labels also matter to voters in multiparty systems such as the Danish system, but they are not as decisive as in US elections, and they do not help the voter in differentiating between the many candidates within a party. ${ }^{4}$

By investigating the crowding-out effects of policy information instead of party cues, our study may show whether crowding-out effects are a more general phenomenon. As we elaborate upon in our description of the experiment, we therefore present policy information in the form of a specific policy position rather than a policy label. We expect that voters use personal characteristics of candidates to serve as proxies for policy positions when such positions are not available. Therefore, policy information might crowd out effects of personal background characteristics in the same way that party identification can: whenever people are presented with candidates without any accompanying policy information, they may rely heavily on the candidate's background characteristics, whereas when the candidate is associated with specific policies, voters may rely heavily on this information and less on the personal background

\footnotetext{
3 Average number of candidates in municipalities was 98 . Viable parties are defined as a parties receiving $>1 \%$ of the votes in the municipality. A minority of candidates ran as independents or for non-viable parties (Statistics Denmark 2018).
}

4 Even in the US context, party cues are often absent to voters, e.g., in primary election where candidates share party affiliation (Kirkland \& Coppock, 2017) 
characteristics. This leads to the hypothesis that information regarding policy positions crowds out the influence of other variables (hypothesis 4).

This crowding out effect will likely be different across different background characteristics and on the different dimensions on which voters evaluate candidates. It is likely that explicit policy information strongly affects voters' inferences from background information to the candidate's policy position, while the effects on inferences to warmth and competence could be smaller. Further complicating this potential crowding out effect, the measures on which voters evaluate candidates are not independent of each other. For example, people are more likely to assign positive personal attributes to politicians with whom they agree (Funk 1999; Bartels 2002). Thus, when policy information affects one type of voter inferences, e.g., on candidate left-right position, this change may indirectly also affect the voter's evaluation on other measures, e.g., warmth. Because of these complex relationships between background characteristics, policy information and candidate evaluations, we refrained from detailed hypotheses regarding the effects of providing voters with policy information in our preregistration. However, the analysis explores in detail the degree to which the crowing-out effects of policy information differs between different background characteristics and between the different dimension on which voters evaluate candidates.

\section{Experiment}

To test our hypotheses, we conducted a survey experiment. The study was pre-registered on Open Science Framework prior to any data collection. ${ }^{5}$ The experiment was conducted in a

\footnotetext{
${ }^{5}$ Preregistration available at: https://osf.io/6dzmx/?view_only=717d4ab86aca4f0f9e5e87af0b13e2fd. We deviate from our pre-analysis plan on two counts. First, the preregistration erroneously included the word "parents" in two hypotheses regarding candidate occupation (making hypotheses $3 \mathrm{C}$ and $3 \mathrm{D}$ identical to $2 \mathrm{~B}$ and $2 \mathrm{C}$ ). As is clear from the context, these hypotheses should be about the occupation of the candidates not their parents, and we have therefore corrected the wording. Second, we originally planned to test the hypotheses regarding the effects of gender, parental background and occupation in a regression model without interactions between background
} 
commercial web panel (Voxmeter). It is not possible to self-select into the panel, and the company continuously recruit new members from random samples of the Danish population. For their participation, panel members receive points redeemable for lotteries, charitable donations etc. For our study, 7.914 existing panel members were invited by email to participate. 2,597 respondents started the survey, and 2,400 completed the entire survey, yielding a response rate of $30.3 \%$ and a completion rate of $92.4 \% .{ }^{6}$ Completion rate among respondents exposed to the experimental stimuli was $94.8 \%$, and the very limited post-treatment attrition did not differ significantly across the experimental conditions. Our final sample is not a probability sample, but it is demographically diverse and has substantial variation on attitudinal variables: $50.8 \%$ of the sample was female, the ages ranged from 18 to $88(\mathrm{M}=48.6 \mathrm{SD}=17.1)$, and $45.2 \%$ had completed tertiary-level education (college level). Respondents' self-placement on the left-right political scale also revealed a substantial level of ideological variation $(\mathrm{M}=.45, \mathrm{SD}=.27$, scale range: $0-1)$, and the sample was approximately representative on party choice. Furthermore, we note that studies show treatment effects in survey experiments to be remarkable similar across probability and non-probability samples (Mullinix et al 2015, Coppock et al. 2018). For sample and population characteristics, see Appendix A.

characteristics and policy information. However, such models lump together respondents exposed to no policy information with respondents exposed to policy information. Because we - at the same time - assume policy information to interact with background characteristics (c.f. hypothesis 4), we realized that it is problematic to use such models. Therefore, our tests of all of the hypotheses are instead based on regression models in which background characteristics are interacted with the policy information treatment. All of the models originally described in the pre-analysis plan are included in Appendix C. These models still find statistically significant effects of parental background and candidate occupation.

${ }^{6}$ In appendix D we show that this sample size provides us with enough power to detect relatively small effect sizes. 


\subsection{Design}

After answering standard questions on demographics, vote choice, and self-placement on the political left-right scale, respondents were randomly assigned to different versions of a brief description of a fictitious candidate for municipal elections. The experiment was conducted less than a month before the Danish municipal elections in November 2017. These elections are salient national events that attract a great deal of media attention, and the national turnout rate in 2017 was $70.8 \%$ (Hansen 2018).

To test our hypotheses, we varied four attributes of the fictitious candidate: gender, family background, the candidate's own occupation, and the candidate's policy position. With a full factorial design, this yielded 54 unique candidate descriptions $(2$ genders $\times 3$ family backgrounds $\times 3$ candidate occupations $\times 3$ policy positions). Specifically, Gender of the candidate was manipulated by changing pronouns and the first names of the candidates. We used two common Danish names, Anne and Peter, without any clear connotations of socioeconomic background. Family background of the candidate was varied by information regarding the occupation of the candidate's parents (either no information, parents were factory workers, or parents were doctors). The candidate's own occupation was also varied (either no information, employed as a warehouse assistant, or employed as a lawyer). Finally, we varied the policy position of the candidate. In all treatments, the candidate offered a generic, nondescript statement of the motivation to run for municipal elections. In the treatment arm with no policy position, the respondents only saw this. The two other treatment arms additionally contained statements from the candidate regarding care for the elderly. Here, the candidate either advocated for increased public spending on the welfare of the elderly (i.e., a left-leaning policy), or the candidate advocated for increased outsourcing in order to increase efficiency and potentially make room for tax cuts (i.e., a right-leaning policy). Both of these policy positions are well within the range of realistic policy positions in a Danish context, where public welfare is routinely outsourced to private companies (Bhatti, Olsen, \& Pedersen 2008). We used the policy issue of elderly care 
because it is a key area of responsibility for the Danish municipalities, and because it lends itself easily to a manipulation of economic policy positions.

In all treatment conditions, respondents were told that the candidate was 47 years old and had moved to the municipality 30 years ago with his or her parents. We explicitly informed about age and time living in the municipality, because we did not want respondents to infer anything about these characteristics based on the information we varied in the experiment. A further advantage of including such information, as well as the nondescript statements from the candidates, is that all respondents were exposed to treatments of comparable length. All candidate descriptions were 89-125 words in length (mean: 111 words, standard deviation: 13.1).

It is also worth noting that experimental studies of candidates' characteristics sometimes present respondents with two candidates (Carnes and Lupu 2016; Kirkland and Coppock 2017; Wüest and Pontusson 2017). However, similar to our study, several recent studies present one rather than two candidates to respondents (Sadin 2015; Amira 2018; Goggin 2018). To minimize the time and reading demands of our respondents, we opted for such a one-candidate design in our experiment.

\subsection{Measures}

After reading the candidate description, perceptions of personality traits were measured by asking respondents to evaluate how well or poorly different words described the candidate. Perceived competence was measured with the four items: intelligent, competent, credible, knowledgeable, while perceived warmth was measured with the four items: likeable, conscientious, friendly, caring. All of these items have previously been used and validated in trait studies (Koch and Obermaier 2014; Funk 1997; Gonzales, Kovera, Sullivan, and Chanley 1995; Goren 2002; Funk 1996; Schneider and Bos 2014; Fridkin and Kenney 2011; Funk 1999). ${ }^{7}$ A factor analysis showed that the items loaded on two distinct scales, and the items formed highly reliable scales for both

\footnotetext{
${ }^{7}$ We used the Danish translation of these trait questions from Pedersen (2017).
} 
competence (Cronbach's $\alpha=0.89)$ and warmth $(\alpha=0.91)$. The correlation between the two scales is 0.64. Next, perceived policy position of the candidate was measured by letting the respondents place the candidate's position on an 11-point left-right scale of economic policy position, ranging from zero to ten. Finally, respondents were asked to rate their likelihood of voting for the candidate, assuming that the candidate ran in the respondents' own municipality. This was also performed on a $0-10$ scale, with 0 being "very unlikely" and 10 being “very likely.” In our analyses, all scales are rescaled to range from zero to one. The full survey questionnaire can be found in Appendix B.

\section{Results}

In all of the analyses, we use regression models (OLS) to estimate the treatment effects. Detailed results for all of the models are shown in Appendix C, Table C1. Before analyzing the effects of personal background characteristics, and the interactions between background characteristics and policy information, we briefly report on the main effects of policy positions. Knowing these main effects of policy position makes it more straightforward to interpret subsequent results.

\subsection{The main effects of policy position}

The main effects of policy positions are considerable, as shown in Figure $1 .{ }^{8}$ Focusing first on the perceived left-right position of the candidate (Column 3 in Figure 1), it is not surprising that information on the candidate's policy position has an effect. In fact, the results on this measure can be thought of as a manipulation check: If explicit information on a candidate's policy

\footnotetext{
${ }^{8}$ In all of our figures, we include $95 \%$ confidence intervals. However, confidence intervals can overlap even though the confidence intervals for the difference between the points may exclude zero (Payton et al., 2003). Therefore, we also include the narrower $83 \%$ confidence intervals. When the standard errors for estimates are approximately similar, as is the case in our analyses, non-overlapping $83 \%$ confidence intervals are a good indication that the difference between estimates is statistically significant (Payton et al., 2003). All figures are made in Stata with software from Bischof (2017) and Jann (2017).
} 
position had not affected the perceived left-right position of the candidate, this would indicate a problem with the experimental stimuli or the attention of the respondents. Fortunately, the results show that voters responded to the left-right treatment as intended and that the treatments were relatively symmetric in the sense that the left-wing treatment moved people about as far from the treatment with no policy position as the right-wing treatment did.

Fig 1: Voter Evaluations Conditional on Policy Information
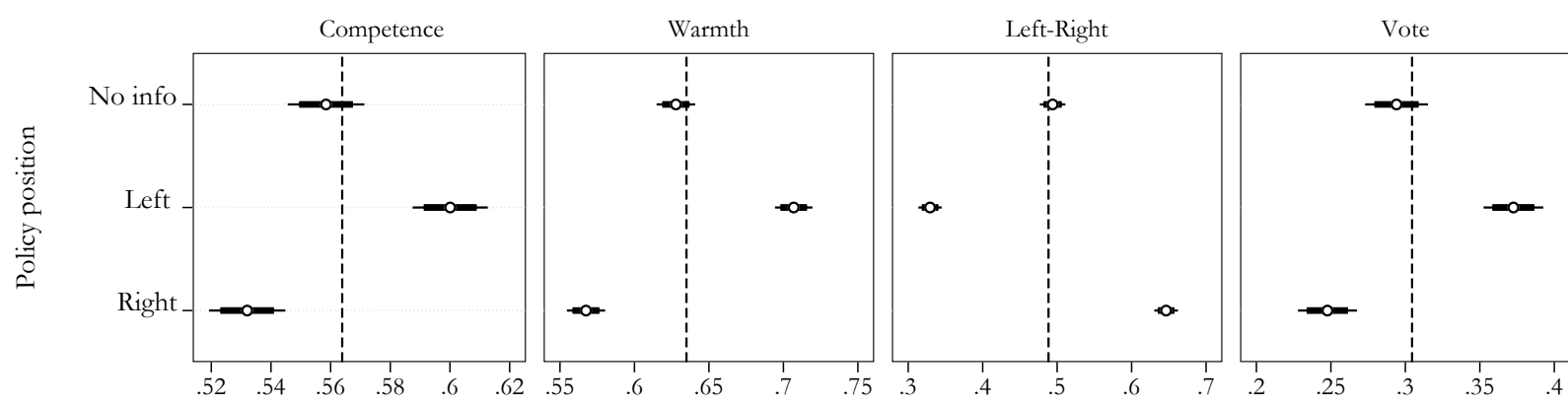

Note: Predicted values with 95\% Confidence intervals (Thicker lines are $83 \%$ C.I.). Vertical dashed lines denote the mean value of variable.

The respondents were also substantially more likely to vote for the left-wing candidate and less likely to vote for the right-wing candidate. While the right-leaning candidate achieved a mean value of just 0.25 on the measure of vote likelihood, the left-leaning candidate achieved a mean value of 0.37 . The popularity of the left-leaning candidate is probably mainly driven by the fact that the left-leaning parties in Denmark have issue ownership on elderly care and social policy in general (Seeberg 2017). While our sample was also slightly left-leaning on the left-right scale, their partisan leanings did not differ markedly from the population of Danish voters (c.f. Appendix A). Finally, the respondents also perceived a left-wing candidate as both warmer and more competent than the candidate with no policy information. Conversely, a right-wing candidate was seen as both less competent and less warm than a candidate with no policy positions. These differences in perceived warmth and competence support the notion that 
people are likely to assign positive attributes to politicians with whom they agree (Funk 1999; Bartels 2002).

How then does policy information interact with candidate background characteristics, and what influence do background characteristics have on their own? In the following sections, we investigate the effects of gender, parental background, and candidate occupation, and we investigate whether the effects of these background characteristics are crowded out when voters are provided with policy information.

\subsection{The Effects of Candidate Gender and Policy Positions}

The combined effects of gender and policy positions are illustrated in Figure 2. As is clear from the top row in Figure 2, there are no substantial differences in voters' perceptions of male and female candidates when there is no explicit policy information in the description of the candidate. On the measure of perceived warmth, the mean scores of a male and a female candidate are practically identical, differing just 0.002 on the scale ranging from zero to one (this difference is statistically insignificant, $\mathrm{p}=.906)$. Thus, these results do not support hypothesis $1 \mathrm{~A}$. On the perceived left-right position of the candidate, female candidates are perceived to be slightly to the left of male candidates, but the difference is just 0.03 , and the difference is not statistically significant $(\mathrm{p}=0.069)$. We therefore also reject hypothesis $1 \mathrm{~B}$. Finally, as illustrated in the rightmost graph in the top row of Figure 2, there are no substantial or statistically significant differences on likelihood of voting for a male versus a female candidate $(\mathrm{p}=.833)$. Based on this, we also reject hypothesis $1 \mathrm{C}^{?}$

\footnotetext{
${ }_{9}^{9}$ As noted, we did not hypothesize any differences on perceived competence of male and female candidates. An exploratory analysis confirmed that there was no significant difference on this measure $(\mathrm{p}=.723)$.
} 
Fig 2: Voter Evaluations Conditional on Candidate Gender and Policy Information

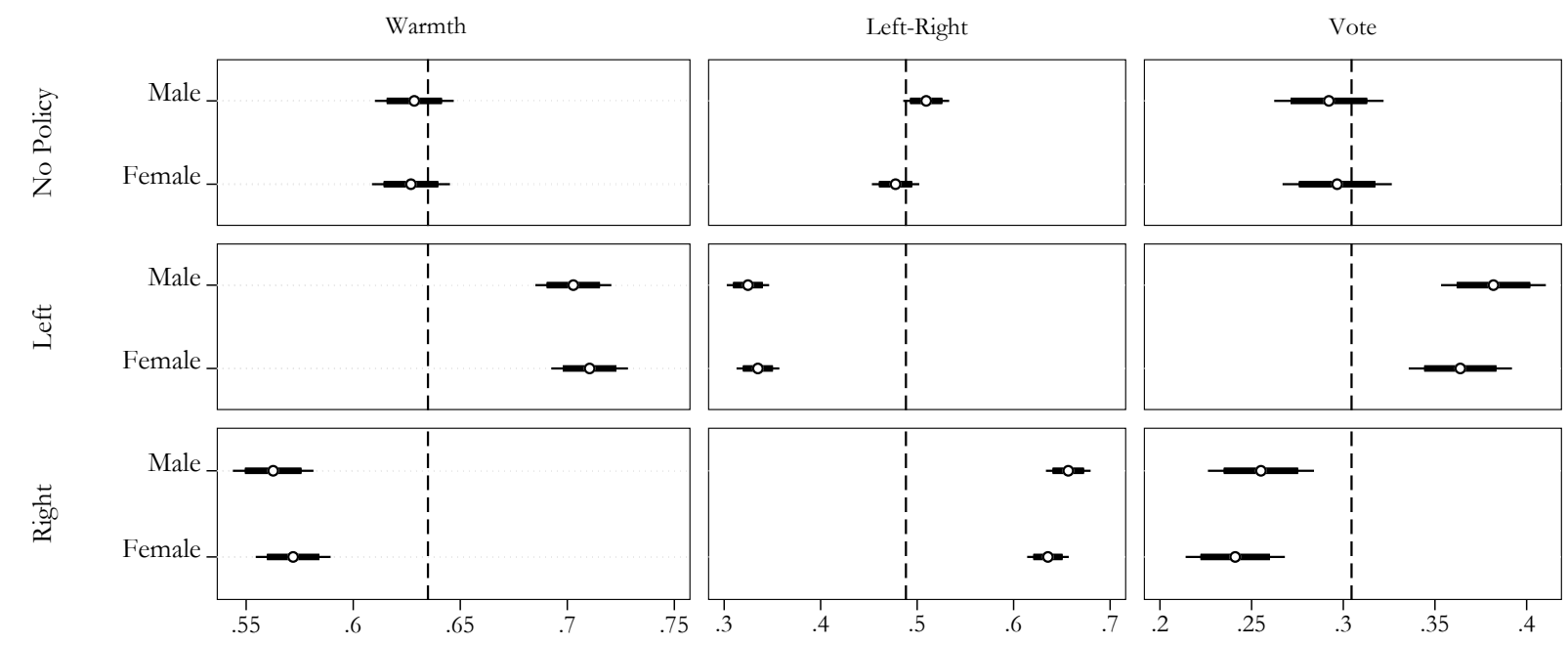

Note: Predicted values with 95\% Confidence intervals (Thicker lines are $83 \%$ C.I.).

Vertical dashed lines denote the mean value of variable.

What then happens to the perceptions of male and female candidates when policy information is present in the candidate descriptions? Of course, policy information cannot crowd out effects of candidate gender if there are no effects of gender to start with, but policy information could potentially amplify the effects of gender. However, as illustrated in rows 2 and 3 of Figure 2, the presence of policy information does not statistically significantly moderate the effects of candidate gender. While the inclusion of policy information clearly affects perceptions of the candidate, the effects are uniform across male and female candidates. Thus, on candidate gender, hypothesis 4 is not supported.

\subsection{The Effects of Parental Background and Policy Positions}

Next, we investigate the effects of parental background, conditional on policy information. These effects are illustrated in Figure 3. The top row of Figure 3, which illustrates the effects of parental background when there is no policy information, shows that voters do respond to the parental background of a candidate. Consistent with hypothesis $2 \mathrm{~A}$, voters perceive candidates with working-class parents to be warmer, both when we compare to a candidate description without information regarding the parents $(\mathrm{p}=.001)$ and when we compare to a candidate with parents that 
were doctors $(\mathrm{p}=.001)$. Similarly, consistent with hypothesis $2 \mathrm{~B}$, the candidate with working-class parents is perceived to be substantially to the left of the candidate without information on parental background $(p<.001)$ and to the left of the candidate with doctors for parents $(p<.001)$. However, disconfirming hypothesis $2 \mathrm{C}$, we find no evidence of voters being more inclined to vote for a candidate with working-class parents. While the candidate with working-class parents appears to be slightly more popular than the candidate with doctors for parents, the difference is substantially small, and it is statistically insignificant $(\mathrm{p}=.488) .{ }^{10}$

Fig 3: Voter Evaluations Conditional on Parents' Occupation and Policy Information

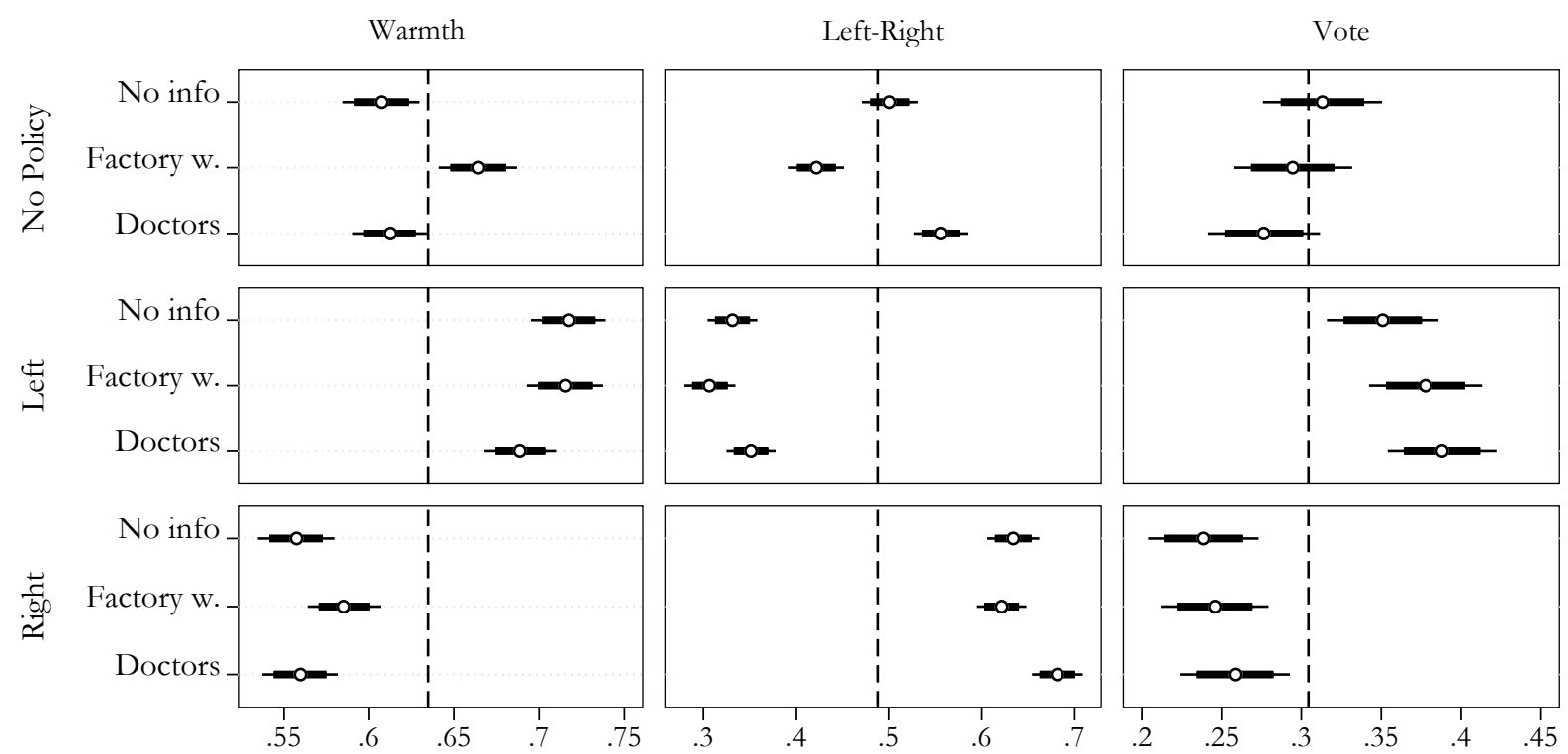

Note: Predicted values with 95\% Confidence intervals (Thicker lines are $83 \%$ C.I.). Vertical dashed lines denote the mean value of variable.

The substantial differences in voter perceptions of candidates with different family backgrounds seem to be attenuated when the candidate's policy position is provided. For example, when the policy position is not known (top row), the child of factory workers is perceived to have a warmth

\footnotetext{
${ }^{10}$ We did not hypothesize any differences on perceived competence of candidates with different parental backgrounds. An exploratory analysis confirmed that there were no statistically significant differences between candidates without information on parents' occupation, candidates with factory-worker parents, and candidates with doctors for parents ( $\mathrm{p}>.2$ for all comparisons).
} 
that is 0.06 higher than the child of parents without a specified occupation. When the policy position is known to be left-leaning (middle row), this warmth premium for the workers' child becomes substantially smaller and almost disappears. There are similar attenuating effects of policy information when the revealed policy position is right-leaning (bottom row) and when comparing the child of factory workers with the child of the doctors, but these effects are not statistically significant. Thus, the results only provide partial support for the notion that information about policy crowds out the effects of parental background on the perceived warmth of a candidate.

The results of policy information are clearer when looking at the perceived left-right placement of the candidate. When the policy position of a candidate is revealed, the effects of parental background are strongly attenuated. The difference between a child of workers and a child of doctors become significantly smaller, both when the revealed policy position is leftleaning $(\mathrm{p}=.002)$, and when the revealed position is right-leaning $(\mathrm{p}=.010)$.

On vote likelihood, we also see an indication of a moderating effect of policy information. The candidate with doctors for parents is less popular than a candidate without parental information and a candidate with factory-worker parents when there is no information regarding the policy of the candidate. However, when the candidate has a left-wing position, the doctor becomes slightly more popular than the other candidates. The advantage of having a leftleaning policy, as opposed to no explicit policy is statistically significantly larger for the candidate with doctors as parents than it is for the candidate with no parental information $(p=.040)$. However, this result should only be treated with caution, as none of the other comparisons of electoral support showed statistically significant marginal effects.

\subsection{The Effects of Candidate Occupation and Policy Positions}

Finally, we focus on the occupation of the candidate and the interaction between occupation and policy information. The results are shown in Figure 4. We hypothesized that a candidate with a working-class job (warehouse assistant) would be perceived as warmer, more left-leaning, but also less competent than a candidate with an upper-middle class job (lawyer). When we look at 
the conditions without explicit policy positions (top row), these expectations are mostly supported. A lawyer is seen as slightly more competent than a warehouse assistant and a candidate without occupational information, although the differences are small, and statistically insignificant when comparing the lawyer and the assistant. Thus, these results do not strongly support hypothesis 3A. On warmth, the differences are more marked, and they favor the working-class candidate. While a candidate employed as a warehouse assistant is not perceived to be warmer than a candidate without information on occupation, the warehouse assistant is perceived to be warmer than the lawyer $(\mathrm{p}=.002)$, supporting hypothesis $3 \mathrm{~B} .{ }^{11}$

On perceived left-right position of the candidate, we also find support for the hypothesis that voters perceived a working-class candidate to be more to the left than an upper-middle class candidate (hypothesis 3C). The warehouse assistant is perceived to be to the left of the lawyer $(\mathrm{p}<.001)$, and the lawyer is perceived to be to the right of the candidate without information regarding occupation $(\mathrm{p}=.011)$. Finally, following hypothesis 3D, we also expected that voters would be more likely to vote for the warehouse assistant than the lawyer. This is also what we see. On likelihood of vote, the warehouse assistant achieves a mean score of 0.32 , which is statistically significantly higher than the lawyer's score of $0.27(\mathrm{p}=.045)$.

Thus, taken together these results seemingly align well with previous studies finding that working-class candidates have an overall electoral advantage over upper-middle class candidates (Campbell and Cowley 2014b; Wüest and Pontusson 2017; Carnes and Lupu 2017). However,

\footnotetext{
${ }^{11}$ One might suspect that these results could depend on specific combinations of a candidate's family background and own occupation., e.g., that a candidate working as a warehouse assistant would be perceived to be less competent if this candidate had doctors for parents (and thereby "underachieving," compared to the parents). To check for this, the exploratory models in appendix C, table $\mathrm{C} 4$ show the results from models in which we interact candidate family background and occupation. These models revealed no statistically significant interactions between candidate family background and occupation on any of the dependent variables.
} 
these results change markedly once we add explicit policy information to the candidate descriptions.

Fig 4: Voter Evaluations Conditional on Candidate Occupation and Policy Information

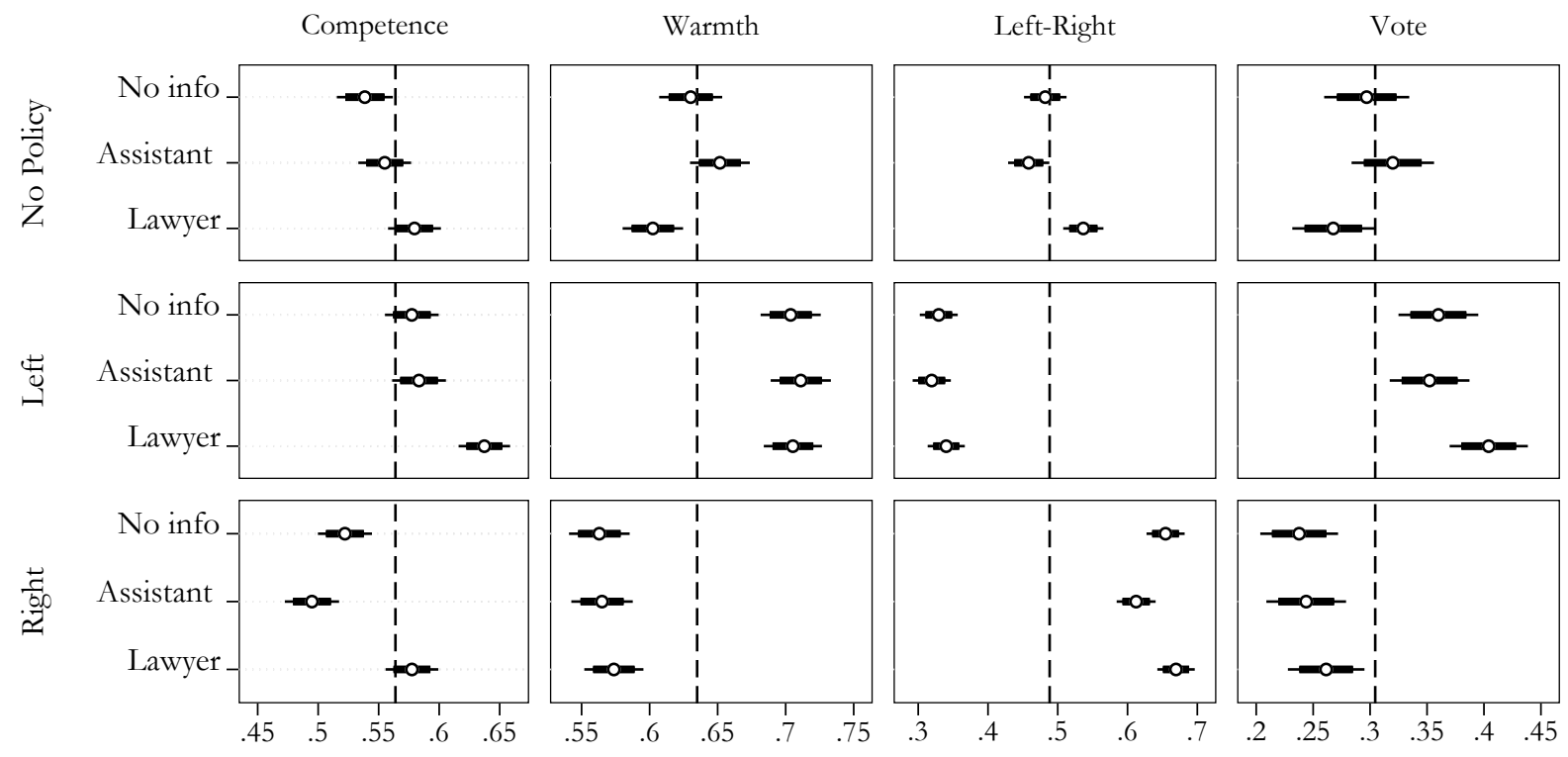

Note: Predicted values with $95 \%$ Confidence intervals (Thicker lines are $83 \%$ C.I.).

Vertical dashed lines denote the mean value of variable.

When the respondents were not informed about the policy position of the candidate (top row), the lawyer was perceived to be statistically significantly more to the right on the political spectrum than the other candidates. However, when the candidate explicitly proposes a left-leaning policy position (middle row), the perceived policy position of the lawyer moves more to the left than the position of the assistant does $(\mathrm{p}=.002)$. As a consequence, the difference in the left-right position of the lawyer and assistant is attenuated. In this condition, a lawyer is perceived to be only 0.04 more to the right of the assistant, which is about a third of the difference $(0.13)$ in the no policy condition. Similarly, when the policy position of the candidate is revealed to be a right-leaning policy (bottom row), the difference between the lawyer and the worker is attenuated to 0.07.

As our respondents generally preferred candidates with a left-leaning policy on elderly care, these results on perceived left-right position seem to provide a good explanation for the results on perceived competence and warmth. In the absence of a policy position, respondents 
inferred that the lawyer was more likely to be right-wing and they were therefore less likely to assign positive traits such as competence and warmth to the candidate (c.f. Funk 1999). Once the policy position of the candidate is revealed, the bias against the supposedly right-leaning lawyer is suppressed, and the lawyer consequently experience a relative boost in their perceived competence and warmth, compared to the assistant.

These interactions between policy information and a candidate's occupation turn out to have a marked effect on vote choice. Without any policy information, the lawyer was the least popular candidate and less popular than the assistant $(\mathrm{p}=0.045)$. With information revealing a right-leaning policy position (bottom row), the lawyer becomes just as popular as the assistant, and when the policy position is left-leaning (middle row), the lawyer even becomes more popular than the assistant $(\mathrm{p}=.038)$. Compared to the no-policy condition, a lawyer promoting the leftleaning policy thus receives a boost in electoral popularity that is substantially larger than the boost received by a warehouse assistant $(\mathrm{p}=.004)$. While the left-leaning policy was generally popular among our sample of respondents, reactions to this policy do depend on the respondent left-right placement. In Appendix C, we include exploratory results, which show that the lawyer always receive a higher electoral boost than the warehouse assistant, when presenting a policy position that is in line with the left-right position of the respondent.

Our results show that the interaction between personal candidate characteristics and policy information can lead to an actual preference reversal among voters. The lawyer is either less or more popular than the assistant, depending on the policy information available to the voter. This finding is quite remarkable, and it has far-reaching consequences for the study of candidate traits and vote choice. We will elaborate on these implications in the discussion. 


\section{Discussion}

This study provides further proof that voters respond to the background characteristics of candidates. Specifically, we have found that voters respond to the parental background and occupation of a candidate, while they are largely indifferent to candidate gender. Male and female candidates are perceived to be equally warm and competent, voters place them at similar points on the left-right scale, and voters are about equally likely to vote for them. These null findings on candidate gender are in line with some previous studies that find no preferences over gender (Carnes and Lupu 2016; Campbell and Cowley 2014b; McElroy and Marsh 2010), but they contrast with studies showing gender preferences (Huddy and Terkildsen 1993; Aguilar, Cunow, and Desposato 2015; Kirkland and Coppock 2017; Wüest and Pontusson 2017; Ono and Burden 2018).

It is important to take the context of our study into account when interpreting the absence of gender effects. First, Denmark has comparatively strong norms regarding general gender equality and women are well integrated into the political system, although still underrepresented (Kosiara-Pedersen and Hansen 2015). ${ }^{12}$ Second, our respondents were not voting for a commander in chief, they were voting for one of many municipal council members responsible for primary schools, retirement homes and other welfare areas. This is important, because voters may prefer male candidates when voting for executives tasked with issues such as defense, crime, etc. (Ono and Burden 2018).

While the voters in our study did not respond to candidate gender, they did respond to parental background and current occupation. When candidate descriptions were without explicit policy positions, candidates with a working-class occupation or working-class parents were perceived to be warmer and more to the left on the political spectrum than candidates with

\footnotetext{
${ }^{12}$ In the 2017 municipal election, $32 \%$ of the candidates running were women. Of those elected, the share of women was 33\% (Statistics Denmark, 2018).
} 
upper-middle class parents. These results may be conditional on the specific occupations used in our study. Our participants clearly reacted when they were told a candidate was working as a lawyer, which may reflect either a general attitude towards upper-middle class candidates or very specific perceptions and attitudes regarding lawyers (c.f. Wüest and Pontusson 2017; Teele, Kalla, and Rosenbluth 2018). Future studies might want to further investigate the degree to which voters respond to the general social class of candidates, and the degree to which they are responding to particularities of a specific occupation.

Ultimately, the most important dependent variable — at least from the perspective of the candidate-is vote choice. In itself, the changes in perceived competence, warmth and left-right placement matter little to the candidate, if they have no effect on their electoral popularity. Our analysis on the effects of personal and background conditions without policy information indicated that the working-class candidate was significantly more popular than the lawyer.

However, this apparent effect of candidate occupation on vote choice leads us to the key result of our study: studies on candidate characteristics may provide us with inaccurate or downright incorrect conclusions on how voters respond to background characteristics, if they do not take the effects of policy information into account. The electoral fates of the warehouse assistant versus the lawyer are notable examples of this: when not informed about the policy position of a candidate, voters perceived a candidate working as a warehouse assistant to be roughly as competent as and significantly warmer than a candidate working as a lawyer. However, if voters were informed that the candidate favored left-leaning policies, the perception of the warehouse assistant was that this candidate was significantly less competent than the lawyer and no higher on the trait of warmth.

These results are most likely a consequence of the way in which voters use background characteristics to infer policy positions. Without policy information, voters infer that the lawyer is to the right of the warehouse assistant (on an issue where respondents generally prefer the left-leaning position). However, when provided with policy information, voters no longer need 
to infer policy position from background characteristics. As a consequence, the lawyer is no longer seen as more right-leaning than the warehouse assistant, and because people are more likely to assign positive personal attributes to politicians with whom they agree (Funk 1999; Bartels 2002), voters now see the lawyer as more competent and warm. The consequence of this is a reversal of preferences: when no policy information is available, voters are more likely to vote for the warehouse assistant than the lawyer. Yet, when the candidate is known to be leftleaning, the voters become more likely to vote for the lawyer than the warehouse assistant.

It is important to remember that candidate choice experiments are not perfect representations of the campaign environment in which real voters find themselves, and an important limitation of our study is that we only use one policy position. Furthermore, our study was conducted within one country. This context is relevant to consider with respect to how the findings would apply in other countries with different gender norms, political cultures and election systems. Recently Arnesen, Duell and Johannesson (2019) have shown that Norwegian voters respond similarly to policy positions as the voters in our studies, and future research could explore if this also applies for other policy issues or party labels in different countries.

Nevertheless, our results show that the studies on the background characteristics need to be mindful of the fact that such background characteristics interact with information on policy when voters evaluate candidates. Specific background characteristics of a candidate are not unequivocally positive or negative to voters. Voters make a host of inferences from background characteristics, and the same characteristics can lead the voter to make inferences about the candidate that are positive on one dimension but negative on another dimension. When policy information is thrown into the mix, such information may crowd out, for example, the negative inferences, and thereby turn an otherwise disadvantageous background characteristic into an electoral advantage. 


\section{References}

Adams, J., Merrill, S., Simas, E. N., and Stone, W. J. (2011). When candidates value good character: A spatial model with applications to congressional elections'. The Journal of Politics 73(1): 17-30.

Aguilar, R., Cunow, S., and Desposato, S. (2015). Choice sets, gender, and candidate choice in Brazil. Electoral Studies 39: 230-242.

Amira, Karyn (2018). Do People Contrast and assimilate Candidate Ideology? An Experimental Test of the Projection Hypothesis. Journal of Experimental Political Science (First view).

Ansolabehere, S., Rodden, J., and Snyder, J. M. (2008). The strength of issues: Using multiple measures to gauge preference stability, ideological constraint, and issue voting. American Political Science Review 102(2): 215-232.

Anzia, S. F., and Berry, C. R. (2011). The Jackie (and Jill) Robinson effect: why do congresswomen outperform congressmen? American Journal of Political Science 55(3): 478-493.

Arnesen, S., Duell, D., and Johannesson, M. P. (2019). Do citizens make inferences from political candidate characteristics when aiming for substantive representation?. Electoral Studies, 57: 46-60.

Bartels, L. M. (2002). The Impact of Candidates Traits in American Presidential Elections. In A. King (ed.), Leaders' Personalities and the Outcome of Democratic Elections. (pp. 44-69). Oxford: Oxford University Press.

Bengtsson, Å., Hansen, K., Harõarson, Ó. P., Narud, H. M., \& Oscarsson, H. (2014). The Nordic voter: myths of exceptionalism. Colchester, ECPR Press.

Bhatti, Y., Olsen, A. L., \& Pedersen, L. H. (2009). The effects of administrative professionals on contracting out. Governance, 22(1), 121-137.

Bischof, Daniel (2017). New Graphic Schemes for Stata: Plotplain and Plottig. Stata Journal 17(3): 748-759

Brady, H. E., and Sniderman, P. M. (1985). Attitude Attribution: A Group Basis for Political Reasoning. American Political Science Review, 79(4): 1061-1078.

Campbell, D. E., Green, J. C., and Layman, G. C. (2011). The party faithful: Partisan images, candidate religion, and the electoral impact of party identification. American Journal of Political Science 55(1): 4258.

Campbell, R., and Cowley, P. (2014a). Rich man, poor man, politician man: Wealth effects in a candidate 
biography survey experiment. British Journal of Politics and International Relations 16(1): 56-74.

Campbell, R., and Cowley, P. (2014b). What voters want: Reactions to candidate characteristics in a survey experiment. Political Studies 62(4): 745-765.

Campbell, R., and Cowley, P. (2015). Attitudes to moonlighting politicians: Evidence from the United Kingdom. Journal of Experimental Political Science 2(1): 63-72.

Carnes, N., and Lupu, N. (2016). Do Voters Dislike Working-Class Candidates? Voter Biases and the Descriptive Underrepresentation of the Working Class. American Political Science Review 110(4): 832844.

Carnes, N., and Sadin, M. L. (2015). The “Mill Worker’s Son” Heuristic: How Voters Perceive Politicians from Working-class Families—and How They Really Behave in Office. The Journal of Politics 77(1): $285-298$.

Coppock, A., Leeper, T. J., \& Mullinix, K. J. (2018). Generalizability of heterogeneous treatment effect estimates across samples. Proceedings of the National Academy of Sciences, 115(49), 12441-12446.

Crowder-Meyer, M., Gadarian, S. K., Trounstine, J., \& Vue, K. (2018). A Different Kind of Disadvantage: Candidate Race, Cognitive Complexity, and Voter Choice. Political Behavior, 1-22.

Dahlgaard, J. O. (2016). You just made it: Individual incumbency advantage under Proportional Representation. Electoral Studies 44: 319-328.

Downs, A. (1957). An Economic Theory of Political Action in a Democracy. Journal of Political Economy 65(2): 135-150.

Fiske, S. T., Cuddy, A. J. C., and Glick, P. (2007). Universal dimensions of social cognition: warmth and competence. Trends in Cognitive Sciences 11(2): 77-83.

Franchino, F., and Zucchini, F. (2015) 'Voting in a Multi-dimensional Space: A Conjoint Analysis Employing Valence and Ideology Attributes of Candidates', Political Science Research and Methods 3(2): $221-241$.

Fridkin, K. L., and Kenney, P. J. (2011). The role of candidate traits in campaigns. The Journal of Politics 73(1): 61-73.

Funk, C. L. (1999). Bringing the Candidate into Models of Candidate Evaluation. The Journal of Politics 61(3): 700-720. 
Gift, T., \& Lastra-Anadón, C. X. (2018). How voters assess elite-educated politicians: A survey experiment. Electoral Studies, 56, 136-149.

Goggin, S. N. (2018). How Quickly We Selectively Forget: Experimental Tests of Information Order on Memory and Candidate Evaluation. Political Psychology (early view).

Greene, S. (1999). Understanding party identification: A social identity approach. Political Psychology 20(2): 393-403.

Hansen, K. M. (2018). Valgdeltagelsen ved kommunal- og regionsvalget 2017. Center for Valg og Partier, Institut for Statskundskab, Københavns Universitet.

Hansen, K. M, and Stubager, R. (2017). Opror fra udkanten: Folketingsvalget 2015. Copenhagen: Jurist-og Økonomforbundets Forlag.

Hayes, D. (2010). Trait Voting in U.S. Senate Elections. American Politics Research 38(6): 1102-1129.

Huddy, L., and Terkildsen, N. (1993). Gender Stereotypes and the Perception of Male and Female Candidates. American Journal of Political Science 37(1): 119-147.

Jann, Ben (2014) Plotting regression coefficients and other estimates. Stata Journal 14(4): 708-737.

Judd, C. M., James-Hawkins, L., Yzerbyt, V., and Kashima, Y. (2005). Fundamental dimensions of social judgment: Understanding the relations between judgments of competence and warmth. Journal of Personality and Social Psychology 89(6): 899-913.

Kam, C.D. (2007). Implicit attitudes, explicit choices: When subliminal priming predicts candidate preference. Political Behavior 29(3): 343-367.

Kamin, L.J. (1958). Ethnic and Party Affiliation of Candidates as Determinats of Voting. Canadian Journal of Psychology 12(4): 205-212.

Kinder, D. R., Peters, M. D., Abelson, R. P., and Fiske, S. T. . (1980). Presidential Prototypes. Political Bebavior 2(4): 315-337.

Kirkland, P. A., and Coppock, A. (2017). Candidate Choice without Party Labels: New Insights from Conjoint Survey Experiments. Political Behavior (First view).

Koch, J. (2000). Do Citizens Apply Gender Stereotypes to Infer Candidates' Ideological Position? The Journal of Politics 62(2): 414-429

Koch, T., and Obermaier, M. (2016). With Heart and (No) Mind? How Recipients Negatively Infer 
Missing Information About Politicians and How This Affects the Assessment of the Speaker. Communication Research 43(7): 972-995.

Kosiara-Pedersen, K., and Hansen, K. M. (2015). Gender differences in assessments of party leaders. Scandinavian Political Studies 38(1): 26-48.

Laustsen, L. (2017). Choosing the Right Candidate: Observational and Experimental Evidence that Conservatives and Liberals Prefer Powerful and Warm Candidate Personalities, Respectively. Political Behavior 39(4): 883-908.

Laustsen, L., and Bor, A. (2017). The relative weight of character traits in political candidate evaluations: Warmth is more important than competence, leadership and integrity. Electoral Studies 49: 96-107. Lawless, Jennifer L. (2009) "Sexism and gender bias in election 2008: A more complex path for women in politics." Politics \& Gender 5(1): 70-80.

Lerman, A. E., and Sadin, M. L. (2016). Stereotyping or Projection? How White and Black Voters Estimate Black Candidates’ Ideology. Political Psychology 37(2): 147-163.

Lupu, N. (2015). Party polarization and mass partisanship: A comparative perspective. Political Behavior, 37(2), 331-356.

Mccurley, C. and Mondak, J. J. (1995) 'Inspected by \# 1184063113: The Influence of Incumbents' Competence and Integrity in U.S. House Elections', American Journal of Political Science 39(4): 864 885.

McDermott, M. L. (1998). Race and Gender Cues in Low Information Elections. Political Research Quarterly 51(4): 895-918.

McElroy, G., and Marsh, M. (2010). Candidate gender and voter choice: Analysis from a multimember preferential voting system. Political Research Quarterly 63(4): 822-833.

Miller, A. H., Wattenberg, M. P., and Malanchuk, O. (1986). Schematic Assessments of Presidential Candidates. American Political Science Review 80(2): 521-540.

Mondak, J. J. and Huckfeldt, R. (2006) 'The accessibility and utility of candidate character in electoral decision making', Electoral Studies 25(1): 20-34.

Mullinix, K. J., Leeper, T. J., Druckman, J. N., \& Freese, J. (2015). The generalizability of survey experiments. Journal of Experimental Political Science, 2(2), 109-138. 
Ohr, D. and Oscarsson, H. (2013). Leader Traits, Leader Image and Vote Choice. In K. Aarts, A. Blais, and H. Schmitt (Eds.), Political Leaders and Democratic Elections. Oxford: Oxford University Press.

Ono, Y. and Burden, B. C. (2018) The Contingent Effects of Candidate Sex on Voter Choice. Political Behavior (First view).

Payton, Mark E., Matthew H. Greenstone, and Nathaniel Schenker (2003). "Overlapping confidence intervals or standard error intervals: what do they mean in terms of statistical significance?." Journal of Insect Science 3(1): 34 .

Pedersen, R. T. (2017). Politicians Appear More Competent When Using Numerical Rhetoric. Journal of Experimental Political Science 4(2): 129-150.

Peterson, D. A. (2005). Heterogeneity and certainty in candidate evaluations. Political Behavior 27(1): 1-24.

Peterson, D. A. (2018). The Dynamic Construction of Candidate Image. Electoral Studies (First view)

Pitkin, H. F. (1967). The concept of representation. London: University of California Press.

Sadin, M. L. (2015). Campaigning with Class: The Effect of Candidate Social Class on Voter Evaluations, (unpublished manuscript).

Seeberg, Henrik Bech (2017). "How stable is political parties' issue ownership? A cross-time, crossnational analysis." Political Studies 65(2): 475-492.

Sen, M. (2017). How Political Signals Affect Public Support for Judicial Nominations: Evidence from a Conjoint Experiment. Political Research Quarterly 70(2): 374-393.

Teele, D. L., Kalla, J., and Rosenbluth, F. (2018). The Ties that Double Bind: Social Roles and Women's Underrepresentation in Politics. American Political Science Review, 112(3): 525-541

West, E. A. (2017). Descriptive representation and political efficacy: Evidence from Obama and Clinton. The Journal of Politics, 79(1), 351-355.

Wüest, R., and Pontusson, J. (2017). Do Citizens Prefer Affluent Representatives? Evidence from a Survey Experiment in Switzerland. Available at SSRN: https://ssrn.com/abstract=3077598 